\title{
Expanding the Ocean Biogeographic Information System (OBIS) beyond species occurrences
}

\author{
Daphnis De Pooter ${ }^{\ddagger}$, Ward Appeltans ${ }^{\S}$, Nicolas Baillyl, Sky Bristol", Klaas Deneudt ${ }^{\ddagger}$, Menashè Eliezer ${ }^{\#}$ \\ , Ei Fujioka ${ }^{\circ}$, Alessandra Giorgetti\#, Philip Goldstein", Mirtha Lewis”, Marina Lipizer”, Kevin Mackay”, \\ María Marín”, Gwenaëlle Moncoiffév, Stamatina Nikolopouloul, Pieter Provoost ${ }^{\S}$, Shannon Rauchi, \\ Andres Roubicek? , Carlos Torres ${ }^{\varsigma}$, Anton P. van de Putte ${ }^{\$}$, Leen Vandepitte ${ }^{\ddagger}$, Bart Vanhoorne ${ }^{\ddagger}$, Matteo \\ Vinci $^{\#}$, Nina Wambijil ${ }^{\ell}$, Dave Watts? ${ }^{?}$ Eduardo Klein ${ }^{\natural}$, Francisco Hernandez ${ }^{\ddagger}$

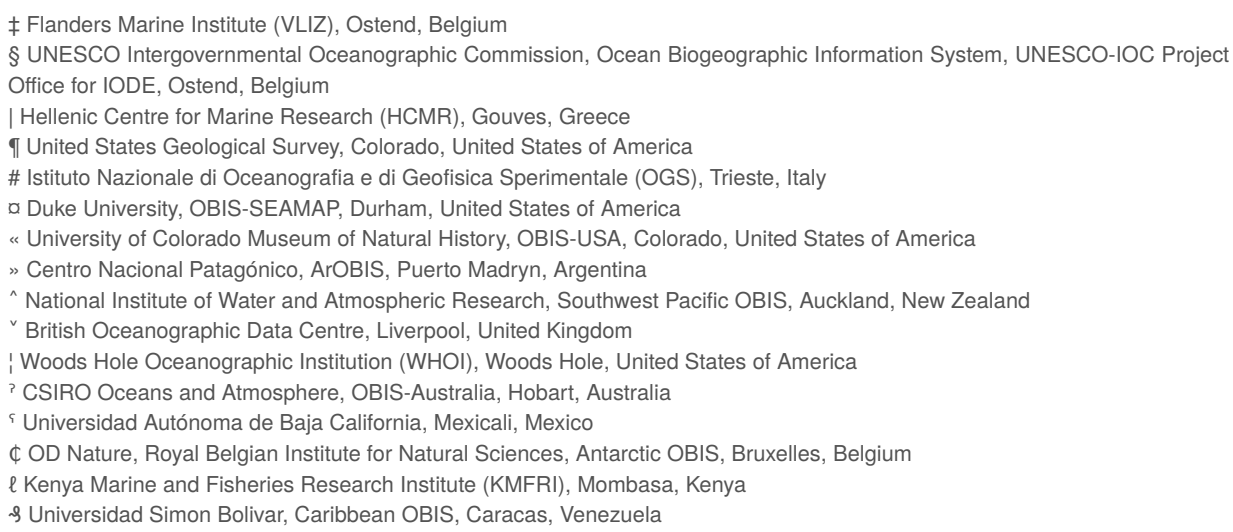

Corresponding author: Daphnis De Pooter (daphnisd@vliz.be)

Received: 11 Aug 2017| Published: 11 Aug 2017

Citation: De Pooter D, Appeltans W, Bailly N, Bristol S, Deneudt K, Eliezer M, Fujioka E, Giorgetti A, Goldstein P, Lewis M, Lipizer M, Mackay K, Marín M, Moncoiffé G, Nikolopoulou S, Provoost P, Rauch S, Roubicek A, Torres C, van de Putte A, Vandepitte L, Vanhoorne B, Vinci M, Wambiji N, Watts D, Klein E, Hernandez F (2017) Expanding the Ocean Biogeographic Information System (OBIS) beyond species occurrences. Proceedings of TDWG 1: e20196. https://doi.org/10.3897/tdwgproceedings.1.20196

\section{Abstract}

The Ocean Biogeographic Information System (OBIS) aims to integrate smaller, isolated datasets into a larger, more comprehensive picture of life in our oceans. Therefore, OBIS 
provides a gateway to many datasets containing information on where and when marine species have been observed. The datasets within OBIS are contributed by a network of hundreds of institutes, projects and individuals, all with the common goal to gain scientific knowledge and to make these data and knowledge easily available to the public.

Until recently, OBIS had solely focused on biogeographic data, in the form of presence of marine species in space and time. Data collected for biological studies however often include more than just presence or abundance. Physical and chemical measurements are often taken concomitantly providing insights into the environmental conditions the species live in. Details on the nature of the sampling methods, equipment used and effort can also be of major importance.

Based on requirements from the growing OBIS community for data archiving and scientific applications, OBIS completed the OBIS-ENV-DATA project in 2017 to enhance its data standard by accommodating additional data types (De Pooter et al. 2017). The proposed standard allows for the management of sampling methodology, animal tracking and telemetry data, and environmental measurements such as nutrient concentrations, sediment characteristics and other abiotic parameters measured during sampling.

The new OBIS data standard builds on the Darwin Core Archive and on practices adopted by the Global Biodiversity Information Facility (GBIF). It consists of an Event Core in combination with an Occurrence Extension and an enhanced MeasurementOrFact Extension Fig. 1. This new structure enables the linkage of measurements or facts quantitative or qualitative properties - to both sampling events and species occurrences, and includes additional fields for property standardization. The OBIS standard also embraces the use of the new Darwin Core term parentEventID, enabling a sampling event hierarchy. 


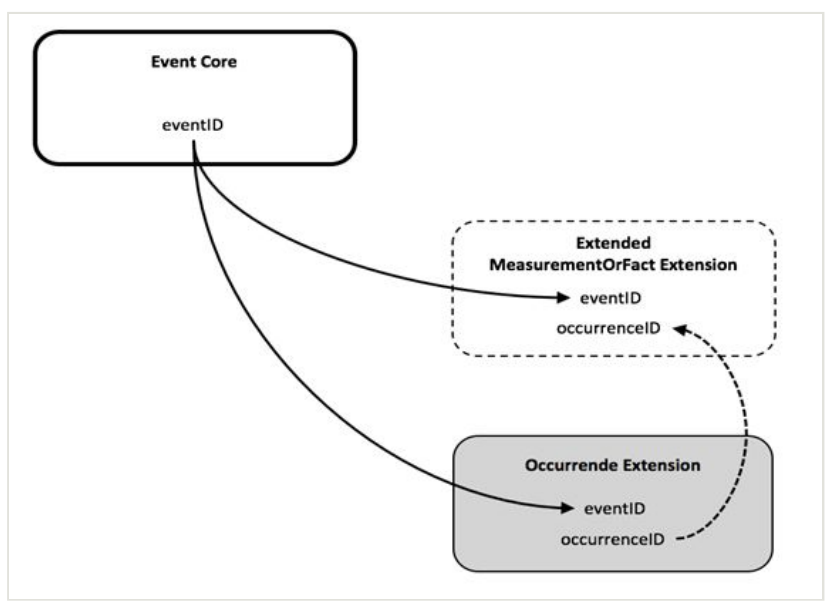

Figure 1.

Schematic diagram showing linkages between the Event Core, the Occurrence Extension and the ExtendedMeasurementOrFact Extension. The IPT's enforcement of the star schema is not broken, but the DwC-A capability is extended with an additional link between both extensions for biotic measurements.

During the follow-up project "OBIS-Event Data", the format will be further fine-tuned during two workshops with two different communities of practice. The first workshop (April 2018) will focus on animal tagging and tracking data, while the second one (October 2018) will tackle macro- and meiobenthos data. The OBIS-Event Data project will also develop the first data products and applications based on the standard and make these tools part of the core OBIS data system output.

We believe that the adoption of this new data standard by the international community will be key to improving the effectiveness of the knowledge base and will enhance integration and management of critical data needed to understand ecological and biological processes in the ocean.

\section{Keywords}

Darwin Core Archive, sample event, species occurrence, environmental data, ecosystem data, telemetry data, data standardisation, oceanographic data

\section{Presenting author}

\section{Daphnis De Pooter}




\section{Funding program}

International Oceanographic Data and Information Exchange (IODE), LifeWatch

\section{References}

- De Pooter D, Appeltans W, Bailly N, Bristol S, Deneudt K, Eliezer M, Fujioka E, Giorgetti A, Goldstein P, Lewis M, Lipizer M, Mackay K, Marin M, Moncoiffé G, Nikolopoulou S, Provoost P, Rauch S, Roubicek A, Torres C, van de Putte A, Vandepitte L, Vanhoorne B, Vinci M, Wambiji N, Watts D, Salas EK, Hernandez F (2017) Toward a new data standard for combined marine biological and environmental datasets - expanding OBIS beyond species occurrences. Biodiversity Data Journal 5: e10989. https:// doi.org/10.3897/bdj.5.e10989 